\title{
FENOMENOLOGIA E CAPOEIRA: JOGOS LUDOMOTRÍCIOS NA FORMAÇÃO DA CRIANÇA NA FASE PUER
}

\author{
Phenomenology and Capoeira: \\ Games Ludo-Motricity in the Formation of the Child in the Puer Phase \\ Fenomenologia y Capoeira: Juegos Ludomotricio en la Formación del Nino de la Fase Puer \\ EDUARDo OKUHARa ArRuda
}

\begin{abstract}
Resumo: O presente ensaio, de orientação fenomenológica, teve como foco a capoeira enquanto jogo ludomotricio na educação da criança na fase puer. O objetivo foi compreender a criança nessa fase, marcada pela linguagem, pelo mundo simbólico e lúdico numa relação com a capoeira como jogo-de-si-mesmo. A roda da capoeira representa um espaço de construção de si-mesmo, onde a criança falante, que se movimenta em relação ao outro, busca sentidos, como a convivência, a afetividade, a criatividade e a percepção de si. Os jogos de si mesmo se traduzem como práxis de autonomia, alteridade e formação. Estar imerso nos jogos de si-mesmo, como no jogo da capoeira, pode significar a ação de compartilhar experiências de solicitude. Na fase puer, os jogos de si-mesmo, ludomotrícios, não são, tão somente, a representação de papéis, mas a presentificação da plenitude desse se movimentar ludomotrício na roda, como jogo de si-mesmo e, portanto, a roda como espaço de construção de sentidos e educação na fase puer. Palavras-chave: Fenomenologia; Capoeira; Jogo; Ludomotrício; Si-mesmo.
\end{abstract}

\begin{abstract}
The following essay, departing from a phenomenological perspective, has its focus on the capoeira as a game of ludomotricity for children's education at the phase puer. The objective is to comprehend the child at this phase, marked by language, by its ludic and the symbolical world in relation with the capoeira as an oneself-game. The capoeira's circle represents a place for the constitution of one's oneself, an area where the speaking child, whose movements occur in relation to the other, can find meanings like living among others, affectivity, creativity and self-perception. The oneself games can be understood as the praxis of autonomy, alterity and self-formation. To be immerse in the oneself games, as the game of capoeira, is to be able to give meaning to the act of sharing solicitude's experiences. At the phase puer the oneself games are deeply involved with the body-ludomotricity. They're not only the representation of a character, but the plenitude of the playing-movements in the capoeira circle, as a oneself game, and, lastly, the capoeira circle as a place of meaning constitution and education at the phase puer.

Keywords: Phenomenology, Capoeira; Play; Ludo-motricity; Oneself.

Resumen: En este estudio, la orientación fenomenológica mira la “capoeira” como juego ludomotricio en la educación del niño de la fase puer. El objetivo es comprender al niño en esta etapa, marcada por el lenguaje, su mundo simbólico y lúdico en relación con la capoeira como un juego-de-sí-mismo. La "roda de capoeira" (un círculo de personas que practican capoeira) es un espacio de construcción de sí mismo, donde el niño hablante se mueve en relación a los otros, buscan direcciones, como la convivencia, la afectividad, la creatividad y el sentido de sí mismo. El juego en sí se traduce como praxis de la autonomía, la alteridad y la formación. Estar inmerso en los juegos de uno mismo, como en el juego de la capoeira, puede significar la acción de compartir experiencias de solicitud en relación a otros. En la fase puer, el juego de si mismo en relación a otros, acción ludomotrícia, no son, por sí solo, representaciones, pero presentificación de la plenitud del movimiento ludomotrício, como jugar a uno mismo y por lo tanto estar en la rueda como espacio construcción de sentido y de educación en la fase puer.

Palabras-clave: Fenomenología; "Capoeira”; Juego; Ludomotrício; Si-mismo.
\end{abstract}

\section{Introdução}

A paideuma, práxis educadora-formadora, já revelava na antiguidade como a cultura grega preocupava-se com a formação nas diferentes idades da vida. Esta reflexão propõe abrir uma discussão de fundo fenomenológico acerca das fases da vida como síntese de experiências vividas intuitivamente e autonomamente, dentro de processos onde cada fase recapitula outra, dialogicamente, tendo como base a fenomenologia e não a ciência empírico-positivista, muito embora possamos abrir um diálogo com outras áreas.
Algumas questões filosóficas se colocam para repensarmos as idades da vida. O que são as idades da vida? Qual a relação que uma fase tem com a outra? Quem sou em determinada fase da vida? Entre outras. No cogito ergo sum cartesiano existe um eu que se prolonga por toda vida, mas esse cogito, entretanto, não se sustenta mais, e a fenomenologia brota, nesse sentido, como abertura para uma nova compreensão das fases da vida. A fenomenologia tem a ver radicalmente com sentidos, e se põe como uma busca descritiva do modo de ser das coisas, como exemplo, o modo de ser das fases da vida. A vida se constitui de fases, e tratar das fases requer uma aproximação 
com a fenomenologia, pois as idades da vida estabelecem relações com o corpo, com a motricidade, com a linguagem e, portanto, com a vida.

Nossa perspectiva tem como fonte teórico-filosófica a fenomenologia, portanto, partirmos das experiências vividas nas diferentes fases vividas para discutir as idades da vida. A despeito da psicologia do desenvolvimento da infância ser de um campo epistemológico empírico, a mesma pode contribuir com nossas reflexões acerca das idades da vida, considerando, especialmente, que o empírico se faz avidamente presente no imaginário social, mas é justamente a fenomenologia que se põe como solo de inspiração na incursão das reflexões aqui apresentadas.

Aspectos empíricos, a exemplo dos estudos ultrassonográficos dos movimentos fetais, podem contribuir na compreensão do corpo-feto. Mas o que nos provoca, necessariamente, é compreender que esse corpo se constitui como corpo pré-linguístico, intencional e que está visceralmente acoplado ao corpo da mãe e em contato com o mundo, o que já lhe confere a constituição da sua corporeidade.

A sedimentação da corporeidade se dá de modo indissociável, e não de modo compartimentado, estanque, como historicamente propugnou a perspectiva empírico-positivista. O corpo inicia seu desenvolvimento motrício, como o andar, ao tempo em que tem início o seu linguagear, assim, tornando-se possível pensar sobre um corpo que se desenvolve no movimento e na linguagem, dialeticamente.

Mas a questão central que se põe nessa discussão, é compreender como a criança na fase puer, a partir do vivido, sedimenta sua corporeidade, seu modo de ser e estar no mundo. A fenomenologia nos inspira a perceber a linguagem como expressão de significação do mundo, pois na medida em que a criança faz uso da linguagem ela se põe em condição de relação e interferência no mundo, apropriando-se, portanto, ainda mais das coisas do mundo, mundanizando-se, organizando-se e ampliando horizontes de sentidos. As idades da vida constituem sínteses de desdobramentos das experiências vividas, assim, a problemática aqui tratada aponta para a desafiadora questão: Como a fenomenologia pode contribuir para uma melhor compreensão da motricidade do corpo puer em relação à capoeira e, ainda, qual a contribuição dessa discussão no campo da educação?

Nosso empreendimento filosófico, a partir da fenomenologia, volta-se à educação, que se põe como uma questão filosófico-antropológica, pois é imanente a vida humana. O objetivo foi compreender a criança na fase puer, marcada pelo mundo mágico-imaginário, suas relações com a dimensão do ludus, da capoeira como jogo motrício e jogo-de-si-mesmo e, assim, pensar nas contribuições da fenomenologia para descrever elementos do modo de ser criança, especificamente, da fase puer.

\section{Fenomenologia das idades: Novos horizontes para pensar as fases da vida}

As idades ou fases da vida se articulam entre si, são marcadas por experiências vividas típicas de cada fase e, assim, conferindo a cada uma delas aspectos que lhe são próprios, então podemos falar, fenomenologicamente, do modo de ser de cada fase.

El tiempo histórico por supuesto es continuo, pero está articulado en dos sentidos: tiene una articulación menor, que son las generaciones, y una articulación mayor, una especie de macroestructura, que son las épocas. Es decir, la historia transcurre en diferentes épocas, cada una de las cuales representa una forma de vida en un nivel histórico y hay además - dentro de cada época - una articulación en diversas generaciones. Algo parecido ocurre en la vida: la vida también es continua desde el nacimiento hasta la muerte, pero está articulada, articulada en edades. Y eso ha sido evidente siempre, desde las culturas más antiguas se ha reconocido la pluralidad de edades y se ha tratado, en cierto modo, de definirlas (Marías, 2012, p. 49)

A fenomenologia trata da experiência originária e no caso da linguagem, a fenomenologia interessa-se, especialmente, pela linguagem vivida enquanto experiência do próprio corpo.

Partimos do vivido da educação (teorias, conceitos, dados empíricos, etc. são suspensos provisoriamente). A vivência da educação é inseparável da vida e nos acompanha em cada passo. A experiência da educação nos abre a percepção de um ser humano que se desenvolve educando-se. A experiência da educação nos remete de imediato à fenomenologia genética que revela a constituição do ser humano em sua formação no tempo. O ser humano revela suas características essenciais em formação. $\mathrm{O}$ ser humano está sendo. A educação aparece na base da antropogenética. (Josgrilberg, 2015, p. 9).

O ser humano está sendo, é ser no tempo, e a fenomenologia permite que alcancemos a compreensão de que temos uma experiência em cada fase da vida. A fenomenologia permite perceber a experiência originária e evidências de aspectos essenciais dessas fases, visto que a partir das vivências em cada fase, torna-se possível apreender aspectos para compreender mais sobre as fases da vida.

Um exemplo clássico: as idades da vida em relação à apropriação do corpo e da linguagem. Cada fase é observada em relação ao todo e não como uma fase explicativa da outra. a) o corpo não falante do infans (infans = não falante); b) o corpo falante do puer; c) corpo que se transforma na busca de outro modo de relação consigo mesmo e com o discurso, o corpo adulescens (Josgrilberg, 2015, p. 12). 
Nesse sentido, há diálogos a fazer com a epistemologia empírica para compreender algumas questões como, por exemplo, a audição que é representacional de um primeiro contato do corpo-feto com o mundo. Estudos sonográficos e ultrassonográficos, auxiliam, empiricamente, a entender o desenvolvimento humano na vida intrauterina.

A fenomenologia abre a possibilidade de uma compreensão dialética entre um mundo onde cabem muitos mundos. A abordagem fenomenológica do mundo trouxe uma nova contribuição para a compreensão e o reconhecimento do mundo cotidiano como um saber em face de outras formas de saber, como o científico. O mundo vivido do cotidiano, o Lebenswelt (Husserl) antecede o mundo da ciência. Tanto a ciência empírica quanto a fenomenologia respondem em última instancia ao mundo vivido do cotidiano, solo e ponto de partida para toda investigação qualquer que seja ela (Josgrilberg, 2015, p. 9).

Destarte, a fenomenologia pode apropriar-se de pesquisas empíricas para compreender melhor a criança e seu desenvolvimento, caso isso se constitua necessário. É presumível, portanto, atermo-nos a vivência do sujeito, como a vivência do corpo infans, descrever a vivência da criança não falante, sem as teias das teorias, isto é, a partir das experiências vividas da própria criança, compreender o mundo infans. É preciso que partamos das experiências vividas, originarias. Nesse sentido, a fenomenologia nos dá pistas de que a criança aprende mais passivamente, na experiência vivida, na cultura, do que na educação sistemática.

Essas breves indicações para mostrar que a abordagem fenomenológica da antropogênese educativa do ser humano contribui com perspectivas que não são as mesmas da investigação empírica, mas que oferecem subsídios para dialogar com as pesquisas empíricas. Como estas, aquelas são também vitais para a visão compreensiva e a possibilidade de pensar mais profundamente as atitudes essenciais da pedagogia. O exemplo das idades da vida é apenas ilustrativo dessa abordagem (Josgrilberg, 2015, p. 14).

Na perspectiva fenomenológica, o ser humano é um ser de abertura e, nesse sentido, é possível compreender que o corpo está posicionado para absorver a linguagem e apropriar-se da cultura em contato com o outro. O corpo é posicionado para o mundo, a partir da concepção de corpo-intencional. A criança se movimenta no período intrauterino para desenvolver seu sistema nervoso, o córtex cerebral e o corpo como um todo.

O ser humano é, em uma de suas dimensões originárias, a abertura para ser educado. A abertura para o ser educado é uma vivência necessária de todos os envolvidos na relação de convivência e de educação. Essa relação originária pode ser explorada analiticamente desde a forma fetal até a morte do indivíduo (Josgrilberg, 2015, p. 10).

No corpo fetal uma das transformações mais agudas que se apresenta para ele é justamente a audição. O som é um elemento que permite o contato com a cultura. $\mathrm{O}$ feto nasce não falante, mas predisposto à linguagem. A tema- tização da experiência originária e da objetivação fenomenológica dos modos de ser, o sentido e sua encarnação linguística, a corporeidade, o mundo da vida e as formas de vida que ele comporta, além de outras ideias, assume uma importância decisiva para a relação da fenomenologia com a educação e para uma compreensão hermenêutica da educação (Josgrilberg, 2015, p. 9).

A ideia, tributária da filosofia de Merleau-Ponty, concebe a infância de modo existencial a partir de um descentramento. É na outridade, na relação eu-outro, que a corporalidade, isto é, a relação eu-corpo se sedimenta. E o corpo próprio, acompanhado pelo outro, encontra-se no mundo: adultos e crianças habitam o mesmo mundo, diferem apenas no modo de viver nele, de apreendê-lo. Essas ideias são originárias dos Cursos na Sorbonne, ministrados por Merleau-Ponty entre os anos de 1949-1952, quando faz uma fenomenologia da psicanálise e propõe outro olhar sobre a infância. É preciso, portanto, que as crianças experimentam suas infâncias na dimensão onírica, polimorfa, não representacional, a seu tempo (Machado, 2007).

Refletir acerca da infância na perspectiva existencial requer um descentramento, de modo que seja possível subtrair o adulto do centro, bem como as espessuras engendradas no adulto. Dessa maneira, a fenomenologia suscita que a criança não é egocentrada, mas mundo centrada. É na outridade, na relação eu-outro, que a corporalidade, isto é, a relação eu-corpo se constitui. E o corpo próprio, na relação com o outro, encontra-se no mundo. Adultos e crianças habitam, portanto, o mesmo mundo que se distingue apenas no modo de viver nele, de apropriar-se dele. Esses modos estão inseridos num dada temporalidade, numa dada espacialidade, em uma dada cultura, mundaneidade (Machado, 2007).

O uso dessas expressões, de matriz fenomenológica, pressupõe a não existência da dicotomia eu tempo, eu espaço, eu mundo. Portanto, dizer mundaneidade não significa dizer a relação da criança com o mundo, pois ela já se encontra no mundo, encarnada e enraizada nele, de tal modo que a criança está no mundo tanto quanto o mundo está nela.

A fenomenologia se coloca como uma via na compreensão da infância, particularmente a criança pequena, visto que se trata de positivar o ser criança, como ela está, como se apresenta a si mesma, a nós e ao mundo, ao invés de tentar modelar por intermédio de teorias e defini-la, portanto, pelo que ela ainda não tem, na espera de que chegue em outros níveis, como as teorias empírico-desenvolvimentistas pretendem explicar a criança e seu desenvolvimento.

Assim, a fenomenologia da criança é realizada a partir de um olhar antropológico rigorosamente cuidadoso. Todavia, torna-se necessário focar na criança mesma, descentrando o olhar adulto e seus contextos teóricos, onde seja possível pensar que a fenomenologia é uma atitude frente ao outro, uma atitude de paciência, algo que não 
vemos nas disciplinas mais técnicas, imbuídas da ideia de cura ou por ventura na ideia da extinção do sintoma. (Machado, 2007)

A fenomenologia não atua a partir de essencialismos, mas com o modo de ser e estar da própria criança pequena. Merleau-Ponty destaca três principais modos de ser: o polimorfismo, onirismo e a não representacionalidade. O polimorfismo nos permite compreender a inteligência da criança pequena, inteligência vivida no corpo cuja potencialidade plástica lhe possibilita concentrar-se e encontrar-se simultaneamente em diferentes ações, algo que o adulto muitas vezes lê noutra chave, como desatenção e imaturidade. Já o modo onírico revela na criança a sua capacidade para juntar realidade e fantasia, especialmente na expressão de desenhos seus pensamentos e sentimentos. E no brincar de faz-de-conta, a não representacionalidade nos revela uma criança mergulhada na experiência de vida e incapaz de distanciar-se para representar. (Merleau-Ponty, 1990 apud Machado, 2014).

Se pensarmos em sintonia com a reflexão merleau-pontyana sobre a infância, algumas prerrogativas rígidas da psicologia clássica, de alguma forma, desmoronam-se, particularmente muito do que foi construído com base na noção projetiva e desenvolvimentista do mundo da criança. Adultos e crianças vivem sua corporeidade no mesmo mundo, o que difere são, tão somente, nossas apreensões dele. Dessa maneira, a fenomenologia abre outro horizonte para compreender a criança. Nos lança, portanto, para uma praxis infantil que não nos apresenta um lugar definido, linear e previsível.

Não quer, portanto, promover pedagogias eficientes. Trata-se de substituir a ideia de explicar o por quê?, para a compreensividade do como?. Essa compreensão fenomenológica somada à noção merleau-pontyana do ser em situação, desmistifica premissas de resultados comportamentais, saltos, giros desenvolvimentistas, bem como outras formas de psicologia e pedagogia centradas no adulto, mas que não levam em conta o vivido, a existencialidade, nem tampouco a dor e a delícia de sermos o que somos no mundo.

Desse modo, compreende-se que a infância é uma temporalidade dessas experiências, dores e delícias, em seu ritmo e em seu modo próprio de percepção essas experiências que marcam essa fase da vida. Ademais, a fenomenologia da infância dá acenos para um permitir que a criança seja criança, o que ela é, ser criança em essência, sem deixá-la à deriva, a cada acontecimento entre adultos e crianças, ao modo cotidiano, na sua condição mais simples. (Machado, 2007).

\section{0 corpopuer: linguagem e os jogos de si-mesmo}

Para Merleau-Ponty a linguagem é encarnada no corpo. A linguagem está em nós, fazemos linguagem nos fazendo. As diferentes estruturações de si-mesmo se transformam com as etapas da vida. A linguagem não dá conta do vivido. A fenomenologia trata do vivido e a linguagem tem um aspecto que é se descolar do corpo e, assim, reunir condições para exprimir linguisticamente às coisas experimentadas, vividas, como, por exemplo, a consciência do tempo, que é adquirida com a própria da linguagem.

A linguagem nos dá uma dimensão da temporalidade, o ontem, o hoje e o amanha. A fenomenologia trata a linguagem a partir das frases narradas e dos sentidos, e não somente dos signos, campo da semiótica. A semântica para a fenomenologia é muito mais ampla do que para a semiótica, pois a fenomenologia da linguagem compreende a linguagem como recurso gerador do ser humano, que produz linguagem e na linguagem se produz. O bebê, por exemplo, tem uma linguagem que é a linguagem geradora e narrativa. Cabe revelar que a linguagem do ritual, da arte, entre outras, têm relação com a linguagem falada. Embora configurem uma linguagem pré-reflexiva, constituem uma linguagem que prepara a reflexão. Já a imaginação assume um papel de mediadora, dando impulsos entre o pré-reflexivo e o reflexivo

No campo da linguagem narrativa, o que é empírico e o que fenomenológico? Fenomenologia é a sua narrativa de mundo, da sua experiência, o seu thaumázein. A fenomenologia emerge não nas representações sociais empiricamente construídas, por exemplo, a representação social de um determinado grupo configura-se como uma pesquisa empírica, mas é a experiência vivida de mundo do sujeito, como o adulescens, nas suas alterações e mudanças corporais e suas implicações nas relações sociais, portanto, uma compreensão de si-mesmo, que se situa como um dado fenomenológico. Essa é, para nós, a contribuição da fenomenologia para ampliar a compreensão das idades da vida.

A criança começa a falar quando alcança o tempo em que o mundo dos outros propicia uma relação falante com o mundo. Manifesta-se, já nos primeiros anos, um grande interesse pela "leitura" narrativa do mundo. Os mundos falantes com os quais interagem e dependem fornecem horizontes de ação e de conhecimento. A busca de autonomia acontece, por exemplo, no aprender a alimentar-se com as próprias mãos, por aprender a higienizar-se sozinho, por manifestar a vontade pontualmente em muitas circunstâncias. Um passo importante para a plena integração do mundo cultural falante será a aquisição da capacidade de leitura e de escrita que mantêm estreitas relações com as condições iniciais do ouvir. (Josgrilberg, 2015, p. 13).

Nessa perspectiva de matriz fenomenológica, propõe-se o si-mesmo como tarefa, desdobramento e busca de autonomia. O si-mesmo desdobrado é síntese pela vida toda. Mas vale retomar que o próprio feto já entra em relação com a cultura, mesmo no período fetal a criança começa a vivência do si-mesmo. Não obstante, é na fase pós-parto 
que a interação com o mundo se constitui mais efetivamente. O si-mesmo transfigura-se como exercício de individuação e, assim, o falante busca uma individuação cada vez maior. A tarefa de si-mesmo é o desdobramento dessa individuação. Essa síntese de si-mesmo acontece em todas as fases, mas, é mais acentuada na fase do falante.

A partir da compreensão de uma disposição para a individuação, a partir dos exercícios ou tarefas de si-mesmo, propomos os jogos de si mesmo. Por meio de jogos simbólicos, miméticos, de representações de personagens, por exemplo, desenvolve-se a percepção de si-mesmo ou mesmo a sua identidade narrativa.

Esses jogos de si-mesmo podem operar numa dimensão de intersubjetividade presente no mundo onde a presença do outro se traduz como parte de nós. Nós temos acesso a nós mesmos, mas nossa relação conosco é indireta, dá-se pelo outro. A criança aos poucos, na sua temporalidade apreende valores, como disciplina, autonomia e, nesse sentido, os jogos de si-mesmo contribuem para a compreensão da realidade, do conviver bem com os outros. A rigor, o jogo de si-mesmo não pode representar a fuga de si-mesmo, mas o contrário disso, isto é, o acesso de si-mesmo como tarefa e, nessa dobra de si-mesmo, a narratividade de si como identidade.

Os jogos de si-mesmo são importantes para formação da uma identidade narrativa. Não há como viver inteiramente um personagem, pois cada um de nós é o próprio personagem. Encarnar o personagem pode ser algo positivo ou negativo. Há diferentes fases e diferentes jogos de si-mesmo. A criança deve desenvolver a liberdade e também a disciplina e sua responsabilização acerca das tarefas que o cercam em seu mundo, pois é justamente a disciplina que gera a liberdade.

A disciplina é fundamental para que se constitua uma possibilidade de liberdade. A relação disciplina-liberdade se aplica ao corpo. Portanto, há nos jogos de si mesmo uma dimensão fenomenológico-ontológica, isto é, o jogo como parte da vida, como exercício do bem-viver, com disciplina-responsabilidade-liberdade e, ainda, um viver que confere gosto, e faz com que queiramos viver bem saboreando as idades da vida com horizontes ou mundo que se abrem para o ludus, ergo sum.

A fenomenologia, embora comece com atos de consciência não se reduz à consciência. Nossa experiência revela uma quantidade de formações passivas e o nosso corpo também se manifesta ser intencional por uma "intencionalidade operante" que atua num nível que a consciência só se dá conta, quando isso acontece, por um trabalho de análise reflexiva de recuperação. A fenomenologia do corpo, por sua anterioridade passiva, progressivamente se deslocou para o centro de preocupações temáticas da fenomenologia. O corpo humano não pode ser compreendido só como natureza; ele é natureza em relação interativa com a linguagem e a cultura (Josgrilberg 2015, p. 8).
A fenomenologia propõe a imaginação-linguagem como condição da experiência de constituição de mundo e de si mesmo. A mediação da linguagem-imaginação nos fornece uma pista para intuir a gênese do processo educativo. No pensamento de Ricoeur conceitos fundamentais da fenomenologia como a intencionalidade, a percepção, a memória, a imaginação, são postos a serviço da narrativa da vida de modo que a linguagem aparece como a esfera abrangente e de comando criação e ação do ser humano. A linguagem como ficção geratriz e pivô de todo desenvolvimento de sentido se torna a porta da esfera propriamente humana. (Josgrilberg, 2012, p. 8)

Assim, a questão da experiência originária e, portanto, dos modos de ser, o sentido e sua encarnação linguística, a corporeidade, o mundo da vida e os diferentes mundos que a vida comporta, além de outras perspectivas, assume uma importância fundamental para que se estabeleça uma relação da fenomenologia com a educação e, como desdobramento, uma compreensão hermenêutica da educação.

\section{0 corpo na roda: 0 jogo da capoeira como jogo de solicitude na perspectiva de Paul Ricoeur}

Para falarmos de corpo, recorremos a Capalbo, que sensivelmente diz que o corpo

é expressão e manifestação de uma subjetividade, é a maneira de um sujeito estar presente ao mundo, aos outros e às coisas, bem como a maneira de como estas se tornam presentes para o sujeito. $\mathrm{O}$ corpo é uma das formas significativas de linguagem. Nele estão embutidas as questões de valorização de tipos de cultura física, numa dada época da história; questões referentes ao bem estar, à saúde, à dor, à doença, ao processo de envelhecimento etc. Por essa relação " eu-corpo-outro-mundo ", o homem vive a sua corporeidade de modo significativo para si próprio e deseja ser reconhecido, nesse valor significativo, pelos outros (Capalbo, 2003, p. 13).

Capalbo (2003) ainda discorrendo acerca do corpo assevera que o corpo é a expressão de nossa existência, tanto quanto a palavra é a expressão do pensamento. E ainda, que as manifestações de nossa vida como a imaginação, a emoção, o trabalho cultural e artístico, representam manifestações de nossa existência, na mesma medida que representam realizações existenciais.

O corpo deve ser contemplado na sua plenitude. $\mathrm{O}$ corpo não é a prisão da alma, mas a fonte de emancipação do ser. Os gestos e toda a expressão corporal revelam as emoções, as intenções, isto é, é pelo corpo que se estabelecem as relações com o outro e com o mundo. É o corpo a maior expressão dos nossos desejos. (Nunes Filho, 1997).

Partindo dessa análise da unidade corpo e linguagem, encontramos lugar para uma relação com a capoei- 
ra. Corpo, linguagem e movimento. Movimento segundo Gonçalves é dialogar com o mundo, é querer saber sobre as coisas do mundo, pois

ao movimentar-se, o homem relaciona-se com algo que está fora dele, podendo ser com os outros ou objetos. Esses são interrogados sobre seu significado para o indivíduo, constituindo-se o movimentar-se sempre de perguntas e respostas. Ex. a bola é interrogada a respeito de sua capacidade de rolar, pular, etc. $\mathrm{O}$ adversário ou companheiro sobre suas intenções do movimento (Gonçalves, 1994, p. 150).

A capoeira é expressa no corpo, cabe reiterar, a fim de superarmos as concepções empíricas de corpo, que o corpo é corpo natural, físico, mas é também corpo cultural. A cinestesia humana não representa tão somente a auto percepção ou mesmo a sensibilidade orgânica dos movimentos do corpo. A cinestesia humana se dá na fronteira do corpo natural com o corpo cultural. O sistema de contingências motrizes do corpo é portador potencial de sistemas simbólicos. O corpo tem a capacidade de movimentos que se traduzem em gestos simbólicos que nos dão um mundo. $\mathrm{O}$ corpo, portanto, irrompe como fonte da nossa relação com o mundo que vai do sensível ao sentido de suas possibilidades linguísticas. Corpo e mundo se desenvolvem como imanência simbólica um do outro (Josgrilberg, 2015, p. 11). Assim sendo, a espacialidade é a presença mesma do corpo ao seu mundo, o que significa dizer que "sua motricidade, sem se reduzir ao mecânico, comporta uma dimensão de espontaneidade. Esse viés espontâneo liga-se justamente à motricidade corporal e à espacialidade que lhe é intrínseca" (Siviero, 2014, p. 117).

Nesse sentido, para Siviero (2104), a motricidade, distanciando-se do mecanicismo-positivista, da visão objetivista e das ciências que tratam o corpo como objeto biológico, tão somente, é correlata dessa presença e dessa abertura ao mundo sensível; o corpo motrício não possui movimento em si, mas quando está polarizado pelas tarefas que o exterior lhe solicita, está engajado em seu meio sensível, profundamente entranhado e enraizado no seio do mundano.

Assim, espacialidade e motricidade são alterações do ser no mundo do sujeito encarnado, ou duas faces do fenômeno de existir e de se situar num mundo posto pela percepção. "O que significa dizer que sua motricidade, sem se reduzir ao mecânico, comporta uma dimensão de espontaneidade. Esse viés espontâneo liga-se justamente à motricidade corporal e à espacialidade que lhe é intrínseca" (Siviero, 2014, p. 117)

A motricidade é inseparável da dimensão espacial, visto que ela nada mais é do que o seu desdobramento (Siviero, 2014). No que tange a expressão motricidade, Merleau-Ponty desejava mostrar que motricidade representava, em última analise, uma intencionalidade originá- ria no sentido de que o corpo se origina como movimento não apenas porque há espaço, mas porque há um convite ao corpo, vindo do mundo, e que é respondido pelo corpo como movimento. (Merleau-Ponty, 2011)

Há um corpo que transpassa uma simples anatomia e permite uma significação nova. Dessa forma, a motricidade irrompe, em seu movimento e na sua experiência significativa, o espaço do mundo que se põe como horizonte de significações (Siviero, 2014). Após apresentar a estima de si como momento reflexivo da práxis, Paul Ricoeur pergunta se esse visar à vida boa não incorre no risco de um enclausuramento de si sobre si mesmo. Assim, essa busca de realização que pode ser constatada no desejo de bem-viver não excluiria, por desdobramento, a presença do outro, ou mesmo diminuiria a sua importância. Dessa forma, para não correr riscos de uma clausura de si sobre si, o autor de si-mesmo como outro apresenta mais um elemento que há de constituir sua ética, a solicitude.

Voltando à questão da solicitude propriamente dita, Ricoeur é motivado e, ao mesmo tempo, guiado pela questão que versa sobre o aparente paradoxo entre a estima de si e a estima do outro, isso é, entre o primeiro o segundo momento da perspectiva ética, uma vez que esse traz à baila o tema da alteridade, o qual não se ajunta de fora à estima de si, mas que ela desdobra a sua dimensão dialogal até aqui passada em silêncio. Afinal de contas "a estima de si e a solicitude não podem ser vividas e pensadas uma sem a outra. Por isso Ricoeur entende, enfim, a solicitude como "a estima do outro" (Pinto, 2012, p. 52).

O que resta saber ao filósofo é de que modo o tomar consciência de si, que é a estima de si, articula-se com o tomar a consciência do outro, que é a solicitude. Ora, a estima de si provém da capacidade que o ser humano tem de agir no mundo, de avaliá-lo, de avaliar-se a si próprio e suas ações. Destarte, percebe-se, portanto, que o outro não ocupa um lugar sem importância na ética filosófica ricoeuriana, pois relacionar a estima de si à estima do outro, há o desdobramento da noção de similitude, a qual define-se como o fruto da troca entre estima de si e solicitude para outros, onde essa relação de troca legitima a ideia de que não posso estimar o meu eu mesmo sem estimar o outrem como eu mesmo (Pinto, 2012).

\section{Capoeira como jogo discursivo ludomotrício- paideúmico: Educando para a alteridade na fase puer.}

O corpo é o lugar de transação entre natureza e paideuma. Difícil é exagerar sua relevância na fenomenologia. Os mundos que habitamos operam como extensão do corpo cultural (Josgrilberg, 2015). Na perspectiva de um encontro entre subjetividades, comungamos com Rosa ao dizer algo sobre a prática pedagógica. De acordo com a autora, cabe ao educador-facilitador, 
ajudar o educando a responsabilizar-se pelo seu projeto existencial, colocando à sua disposição a tradição cultural herdada. Tal tarefa será mais bem-sucedida se pudermos abdicar daquela estética linear, previsível e homogênea e abrir espaço a outra estética, não-linear, aquela cujo desenho único e intransferível se faz a partir de um verdadeiro encontro entre subjetividades que se dispõem a ensinar e aprender (Rosa, 2002, p. 118).

Essa perspectiva de reinventar, de re-transformar é fundamental para conferir novos possíveis à roda de capoeira. Um movimento corporal que aponta na perspectiva do respeito, do cuidado, da cooperação, da beleza e da plasticidade do corpo que conscientemente se expressa na roda. Reinventar uma linguagem que quer expressar sua individualidade, suas emoções e sentimentos com liberdade, o discurso do corpo.

Um aspecto fundamental do discurso é que ele é direcionado a alguém. Há outro falante que é endereçado o discurso. Assim como no diálogo, há um locutor e um receptor. A presença do par, locutor-ouvinte, configura a linguagem como comunicação. $\mathrm{O}$ estudo da linguagem a partir do ponto de vista da comunicação não começa, no entanto, na sociologia da comunicação. Como Platão afirma, o diálogo é uma estrutura essencial do discurso. Perguntar e responder sustentam o movimento e a dinâmica do falar e, em certo sentido, não constituem um modo de discurso entre outros. Cada ato ilocucionário é uma espécie de pergunta. (Ricoeur, 2000, p. 26).

Para o linguista, a comunicação é um óbvio. As pessoas, efetivamente, falam uma às outras. Entretanto, para uma investigação existencial, a comunicação é um enigma e até mesmo um milagre. Por quê? Porque o estar junto, enquanto condição existencial da possibilidade de qualquer estrutura dialógica do discurso irrompe como um modo de ultrapassar ou de superar a solidão fundamental de cada ser humano. (Ricoeur, 2000).

Este novo aspecto da dialética de evento e significação merece atenção. $O$ evento não é apenas a experiência enquanto expressa e comunicada, mas também a própria troca intersubjetiva, o acontecer do diálogo. "A instância do discurso é a instância do diálogo. O diálogo é um evento que liga dois eventos, o do locutor e do ouvinte". (Ricoeur, 2000, p. 28).

Deste modo, partindo dessa análise da unidade corpo-linguagem, encontramos lugar para uma relação com a capoeira, onde "jogar capoeira é antes de tudo uma gramática corporal. A linguagem é mediada pelo corpo, trata-se de um jogo de perguntas e respostas corporais. (...) o corpo é linguagem, linguagem de corpo, capoeira, corpoeira. Corpo, linguagem e movimento" (Arruda, 2014, p. 70).

O movimento entra nessa perspectiva como a palavra, o léxico. O jogo, por sua vez, entra como discurso. Contudo, sendo a pessoa, o ser que fala no discurso, um ser-no-mundo projetado, aquilo que está dito na fala será a projeção de um mundo, eis, portanto, a distinção entre palavra e o discurso. O discurso é projeção de si, é aquilo que faz com o corpo, portanto, o seu discurso corporal, representa a sua projeção de mundo.

Para Ricoeur o discurso é sempre discurso a respeito de algo, "refere-se a um mundo que pretende descrever, exprimir ou representar. Mas o discurso também é interpessoal, ele se dirige a outro que pode ouvi-lo, prolongá-lo ou mesmo interrompê-lo" (Ricoeur, 1977, p. 46). O discurso diz algo sobre algo. Não apenas um dizer sobre e a recepção sobre algo, mas o exame da consciência do centro do diálogo. Assim, é justamente o discurso que permite a projeção ao outro, a dialogação, o ser-com-o-outro-na-roda. O jogo da capoeira é um jogo discursivo na medida em que é o discurso que permite a projeção do si-mesmo para o outro. Tal projeção implica numa vida examinada como uma vida narrada. Narrar faz parte do processo do reconhecimento de si-mesmo pela narrativa. Nesse sentido, o jogo que não incorpora a discursividade, na perspectiva de Ricoeur, pode ser comparado ao um jogo onde não há a projeção para o outro, não há o jogo dialógico-discursivo, tampouco a identidade mediada pelas narrativas do jogo.

O jogo, enquanto abertura mundana - ou abertura da existência humana ao mundo - é capaz de nos impregnar de uma alegria de viver elementar, ou seja, de uma alegria que é mais que o prazer que dão as coisas divertidas, úteis e agradáveis. Aqui, mundo e realidade não são prévios nem imutáveis, mas em movimento de tornarem-se conosco: um mundo-realidade que está sendo, um mundo-realidade que não é, mas que está por realizar-se, um mundo-realidade que nunca estará plenamente realizado porque ele é comum e tem que ser imaginado junto, isto é, ludicamente partilhado: um mundo lúdico não pode jamais subsistir unicamente por ele mesmo, ele depende sempre da realidade ordinária dos jogadores e dos jogos (Fink citado por Richter, Murilo e Berle, 2012, p. 6).

Huizinga (1999) na sua clássica obra acerca do jogo como elemento da cultura, o jogo se coloca justamente como tudo aquilo que transcende os limites racionais entre o que é físico e o biológico. Sua função a partir daí passa a ter função significante, portanto, encerra um determinado sentido que transcende as necessidades da vida e confere um significado à ação. É na conjugação dos elementos essenciais do jogo, como alegria, divertimento e tensão que encontramos a possibilidade do vínculo da dimensão ludomotrícia com o mundo.

O importante a compreender é que o jogo não é tanto um ato onde nos colocamos em comunicação, mas onde estabelecemos com outros uma diferença que traduz e plasma outros modos de ser e de relacionarmo-nos com aquilo que nos cerca e que são tão reais quanto nós: uma dramatização ou encenação que é aqui sem entretanto ser aqui, que é agora sem portanto ser agora. A textura da realidade persiste enquanto 
temporariamente as coisas aparecem e desaparecem, nascem e morrem. Tomados no instante, não somos senão uma série ordenada de recomeços. (Huizinga, 1999, p. 6)

O tecido linguageiro em que nos constituímos é dado no ato de compartilharmos um mundo, uma narrativa histórica, cultural e social, na qual as narrativas dos pequenos têm a ver com as narrativas dos adultos. Nosso corpo, nosso ser, aprende a estar no mundo, a significar e tornar familiar o mundo em que vivemos a partir da mistura na qual as histórias de nossa existência, resultado de nossa linguagem, nos tornam protagonistas de nossa vida, mas não seus autores. "A autentica identidade se desvela, então, finalmente, como identidade do personagem em uma biografia que ele não escreve, enquanto seu personagem. Não é o autor, mas o personagem” (Barcena \& Mélich, 2000, p. 79). Uma aprendizagem marcada no corpo, constituída na atuação, na interação: na composição de um personagem.

Educar, portanto, é a construção do relato de uma identidade, de uma vida. A ação tem lugar no presente, enquanto a história diz respeito aos fatos e aos acontecimentos. É na mistura lúdica entre a dimensão linguageira do viver, entre presente e passado, no jogo entre linguagem e mundo, que emerge o sentido do viver. Para jogar com a linguagem é preciso jogar com sentidos. A dimensão poética da imaginação emerge então como jogo da e na linguagem que produz narrativas. Por isso a narrativa exige a ação, exige um labor, não basta apenas adotar discursos, é preciso operar com os sentidos do discurso. (Richter, Murilo e Berle, 2012, p. 8)

Ação autônoma é aqui revelada como aquela a ação escolhida e realizada pela própria criança, enquanto condição motrícia, disposição as suas relações com outros, interesse pelo mundo e alegria de surpreender-se com a imprevisibilidade dos acontecimentos gerados pelo ação, portanto, como uma necessidade indispensável do humano desde seu nascimento (Tardos \& Szanto, 2004 apud Richter, Murilo e Berle, 2012)

Na contemporaneidade a preocupação com a educação, desde a tenra idade, tende a objetar e instrumentalizar o processo educativo, como preparação para o mercado de trabalho. Uma educação que polariza ação e discurso, dirigida à superficialidade da informação e não na experiência originária entre corpo e mundo. Nesse sentido, as reflexões até aqui formuladas consubstanciam-se na medida em que consideramos que a dimensão lúdica oportuniza a criança a potenciar sua criatividade, seu si-mesmo e, ainda, entrelaçar uma relação de abertura com a cultura.

Brincar é uma atividade que se opõe ao trabalhar, ou seja, em oposição ás atividades humanas ditas sérias. Para o autor o brinquedo é um elemento da cultura ao alcance da criança, é seu parceiro. Com ele a criança manipula e age. $\mathrm{O}$ processo de criação se desenvolve muito mais. Quanto mais riqueza e diversidade nas experiências oferecidas no seu ambiente, mais estímulo para a criança em sua capacidade de imaginação e criação. Ela reflete o seu pensar nesta forma de agir (Brougére, 1998, p. 295).

O brinquedo se põe como dimensão indissociável da realidade social em que está inserido. A sua função está organicamente relacionada ao valor simbólico que lhe é atribuído pela criança na ludicidade, que é uma conexão entre a ação e a ficção permitindo a representação de mundo por meio de objetos.

Pelos brinquedos a criança imita o mundo em que vive, representa papéis sociais e compreende melhor a vida. Já as brincadeiras socializam, faz com que elas interajam com outras. A brincadeira escapa, em parte, ao brinquedo. Este tem, em contrapartida, funções sociais relativas à maneira como ele é colocado à disposição da criança. Atividades lúdicas permitem à criança desenvolver-se, imaginando, fantasiando, construindo regras e resolvendo conflitos. (Brougére, 1998, p. 297)

Como já fizemos menção, a fenomenologia revela novos possíveis, pensar, sentir e agir, uma vez que a orientação é que em suspensão as teorias cristalizadas a partir do método fenomenológico, a epoché, portanto, buscar a essência do ser criança e o estar aberto a novos possíveis.

Há um horizonte sem fim no que se refere às possibilidades do Ser, o professor e o aluno em seu movimento do ir e vir, do aprender e do ensinar. Nunca se limitando. Um professor que explora as possibilidades reinventa sua prática. Neste trabalho as possibilidades educativas têm como base a Fenomenologia que vislumbram a ação na percepção, observação, afetividade, para a construção da autonomia educativa. A prática pedagógica em Fenomenologia parte da vivência e experiência, a construção da própria história, um aprendizado de vida (Brougére, 1998, p. 299).

Assim, a partir do que nos dispomos a discutir, a fenomenologia das idades da vida, especialmente, a fase puer, os jogos ludomotrícios como a capoeira enquanto jogo de si mesmo, representa uma práxis de possíveis construções de si-mesmo, de um corpo que se movimenta na roda em relação ao outro em busca de construção de sentidos, como a convivência, a afetividade, a criatividade e a percepção de si-mesmo.

Os jogos de si mesmo se traduzem como práxis de autonomia-autenticidade, alteridade e formação. Estar imerso nos jogos de si-mesmo, como o jogo da capoeira, pode significar a ação de compartilhar experiências de solicitude. Os jogos de si-mesmo, ludomotrícios, não são, tão somente, a representação de papéis, mas a própria presentificação de modos de ser e estar em plenitu- 
de nas experiências vividas, portanto, a presentificação de seres motrícios na roda.

\section{Referências bibliográficas}

Arruda, E. O. (2014). Capoeira, Corpo e Educação Física: Por uma pedagogia corporal e humanista. Curitiba: Editora CRV.

Bárcena F.; Mélich J. C. (2000). La educación como acontecimento ético: natalidad, narración y hospitalidad. España: Paidós.

Brougére, G. (1998). A criança e a cultura lúdica. Revista Faculdade de Educação, 24(2), 1-7.

Capalbo, C. (2003). Corpo e existência na filosofia de Maurice Merleau-Ponty. In: Castro, D.S. P. et al. (Org.) Corpo e Existência. São Bernardo do Campo: UMESP.

Fink, E. (1996). Le jeu comme symbole du monde. Traduit par Hans Hildenberg et Alex Lindenberg. Paris: Minuit.

Gonçalves, M. A. S. (1994). Sentir, pensar e agir: Corporeidade e Educação. Campinas: Papirus.

Huizinga, J. (1999). Homo ludens: o jogo como elemento da cultura. São Paulo: Perspectiva.

Josgrilberg, R. (2015). Fenomenologia e educação. Revista Notandum (38), 5-14.

Machado, M. M. (2007). A Flor da Vida: Sementeira para a fenomenologia da pequena infância. 198 p. Tese de Doutorado. Universidade Pontifícia Católica. Programa de Estudos Pós-Graduados em Educação: Psicologia da Educação. São Paulo.

Machado. M. M. (2014). Teatro e infância, mundos de vida (e morte). Revista aSPAs, 4(2), 1-14.

Marías, J. (2012). Las edades de La vida. Notandum 30. (conferencia en Madrid, 1999. Edición: Ana Lúcia Carvalho Fujikura)

Merleau-Ponty, M. (1999). Fenomenologia da percepção. Tradução Carlos Alberto Ribeiro de Moura. São Paulo: Martins Fontes, 1999

Novaes. A.(org.). (2005). Poetas que pensaram o mundo. São Paulo: Companhia das Letras.

Nunes Filho. N. (1997). Eroticamente Humano. 2. ed. Piracicaba: UNIMEP.

Pinto, L. N. A. (2012). A tríplice constituição da perspectiva ética de Paul Ricoeur. Synesis, 4(2), 45-62.

Richter, S. R. S.; Murilo, M. V.; Berle, S. (2012). Aprendendo com o mundo: Ação autônoma e jogo heurístico na educação de bebês. IX ANPED SUL - Seminário de pesquisa em educação da região sul.

Ricouer, P. (2000). A metáfora viva. São Paulo: Loyola.

Ricouer, P. (2002). O único e o singular. Tradução Maria Leonor F. R. Loureiro. São Paulo: Editora UNIESP; Belém, PA: Editora da Universidade Estadual do Pará.
Ricoeur, P. (1977). Interpretação e Ideologias. Rio de Janeiro: Livraria Francisco Alves Editora.

Rosa, S. S. (2002). Brincar, conhecer, ensinar. 3. ed., São Paulo: Cortez.

Siviero, J. M. (2014). Espacialidade e existência: A motricidade em sua significação fenomênica. Universidade de São Paulo. Griot Revista de Filosofia, 9(1).

Sloterdijk, P. (2006). Venir al mundo, venir al lenguaje: Lecciones de Frankfurt. Valencia: Pre-Textos.

Souza, M. N. G. G.; Rojas. J. S. (2010). O brincar uma percepção. Revista Rascunhos Culturais Coxim, 1(2), 289-300.

Souza, S. J.; Kraemer, S. (2009). Política cidade educação: Itinerários de Walter Benjamin. Rio de Janeiro: Contraponto.

Tardos, A.; Szanto, A. (2004). O que é autonomia na primeira infância? In: Falk, J. (Org.). Educar os três primeiros anos: a experiência de Lóczy. Araraquara: JM Editora,. 33-46.

Eduardo Okuhara Arruda - É Doutorando em Educação pela Universidade Metodista de São Paulo. Mestre em Educação Física pela Universidade Metodista de Piracicaba. Graduado em Licenciatura Plena em Educação Física pela Universidade Metodista de São Paulo. Docente no curso de Educação Física da Universidade Metodista de São Paulo e da Uníitalo. Membro do Grupo de Estudos da Fenomenologia das Idades da vida da UMESP. Endereço para correspondência: Rua Solidônio Leite, n. 2315 - Ap. 62 / Bl. 2 - Vila Ivone - São Paulo/SP - CEP 03275-000. E-mail: eduardokuhara@gmail.com

Recebido em 14.02.17 Primeira Decisão Editorial em 21.02.17 Aceito em 19.05.17 